\title{
Thermal and Irradiation Creep Behavior of a Titanium Aluminide in Advanced Nuclear Plant Environments
}

\begin{abstract}
PER MAGNUSSON, JIACHAO CHEN, and WOLFGANG HOFFELNER
Titanium aluminides are well-accepted elevated temperature materials. In conventional applications, their poor oxidation resistance limits the maximum operating temperature. Advanced reactors operate in nonoxidizing environments. This could enlarge the applicability of these materials to higher temperatures. The behavior of a cast gamma-alpha-2 TiAl was investigated under thermal and irradiation conditions. Irradiation creep was studied in beam using helium implantation. Dog-bone samples of dimensions $10 \times 2 \times 0.2 \mathrm{~mm}^{3}$ were investigated in a temperature range of $300{ }^{\circ} \mathrm{C}$ to $500{ }^{\circ} \mathrm{C}$ under irradiation, and significant creep strains were detected. At temperatures above $500{ }^{\circ} \mathrm{C}$, thermal creep becomes the predominant mechanism. Thermal creep was investigated at temperatures up to $900{ }^{\circ} \mathrm{C}$ without irradiation with samples of the same geometry. The results are compared with other materials considered for advanced fission applications. These are a ferritic oxide-dispersion-strengthened material (PM2000) and the nickel-base superalloy IN617. A better thermal creep behavior than IN617 was found in the entire temperature range. Up to $900{ }^{\circ} \mathrm{C}$, the expected $10^{4}$ hour stress rupture properties exceeded even those of the ODS alloy. The irradiation creep performance of the titanium aluminide was comparable with the ODS steels. For IN617, no irradiation creep experiments were performed due to the expected low irradiation resistance (swelling, helium embrittlement) of nickel-base alloys.
\end{abstract}

DOI: $10.1007 / \mathrm{s} 11661-009-0047-3$

(C) The Minerals, Metals \& Materials Society and ASM International 2009

\section{INTRODUCTION}

INTERMETALLIC titanium aluminides are a relatively young class of structural high-temperature materials compared with steels or nickel-base alloys. They combine good high-temperature strength, creep properties, and low density, which makes them candidates for automotive and energy applications. Typical examples are engine parts, turbine blades, ${ }^{[1,2]}$ and turbochargers. ${ }^{[2,3]}$ Besides their low room-temperature ductility, they are mainly limited by their low oxidation resistance above about $800{ }^{\circ} \mathrm{C}$. This limits possible applications to temperatures below their mechanical capabilities. Recent international projects for advanced nuclear fission plants, such as the international generation IV initiative (GIF), search for materials for operating conditions that are different from the ones known for conventional light water reactors. New nuclear power plants will operate at higher temperatures and higher doses and in different environments (helium, liquid metal, molten salt). They are also intended to operate as combined cycle plants for

PER MAGNUSSON, Scientist, JIACHAO CHEN, Senior Scientist, and WOLFGANG HOFFELNER, Leader, are with the High Temperature Materials Project, Paul Scherrer Institut, CH-5232 Villigen PSI, Switzerland. Contact e-mail: wolfgang.hoffelner@psi.ch

This article is based on a presentation given in the symposium "Materials for the Nuclear Renaissance," which occurred during the TMS Annual Meeting, February 15-19, 2009, in San Francisco, CA, under the auspices of Corrosion and Environmental Effects and the Nuclear Materials Committees of ASM-TMS.

Article published online September 11, 2009 electricity production and heat. Suggested reactor technologies are outlined in the roadmap of the GIF. ${ }^{[4]} \mathrm{A}$ very-high-temperature reactor (VHTR) and gas-cooled fast reactor (GFR) operate at high temperatures and use helium as a coolant. An environment such as helium could provide a basis for the use of intermetallics at its strength limits rather than at its oxidation resistance. The fact that the material can be cast would, in principle, allow simple and relatively cheap production of components (control rod elements, heat exchanger parts, etc.). While the creep properties at intermediate temperatures have been studied in numerous publications, ${ }^{[1,5-10]}$ the data of creep properties at temperatures above $800{ }^{\circ} \mathrm{C}$ are still scarce in the literature.

Therefore, information on high-temperature creep is very important for the evaluation of $\gamma$-TiAl as structural material for helium-cooled reactors. The evaluation of $\gamma$-TiAl for nuclear applications also requires knowledge of irradiation properties. Irradiation creep was investigated using helium implantation. This method limits the sample thickness to $200 \mu \mathrm{m}$ to obtain the required through irradiation. Based on these data and the existing literature data, an assessment of the mechanical capabilities of this cast titanium aluminide for structural applications in advanced nuclear plants is performed. Comparisons will be made with the nickel-base alloy IN-617 and the ferritic oxide-dispersion-strengthened alloy PM2000. This material was developed at Plansee (Austria) for high-temperature applications. It consists of a ferritic matrix containing about 19 pct $\mathrm{Cr}$ and about 5 pct Al. The average size of dispersoids is $25 \mathrm{~nm}$. The nickel-base alloy was not included in the irradiation 
creep comparison, because the irradiation properties are better for ferritic alloys than for austenites and nickel is very prone to helium embrittlement.

\section{MATERIAL AND EXPERIMENTAL CONDITIONS}

The investigations were performed with a $\gamma$-TiAlbased intermetallic alloy of type Ti-46Al-2W-0.5Si (at. pct), called ABB-2. ${ }^{[11]}$ The material was available in the form of cast bars with a diameter of about $14 \mathrm{~mm}$. The chemical composition of the alloy is given in Table I. A typical microstructure of the material in as-received condition is shown in Figure 1. ABB-2 is a two-phase $\gamma$-TiAl consisting mainly of grains with lamellar microstructure but also of grains with other duplex microstructure. The two phases are a $\gamma$ phase (TiAl phase with $\mathrm{L} 1_{0}$ crystal structure) and an $\alpha_{2}$ phase $\left(\mathrm{Ti}_{3} \mathrm{Al}\right.$ phase with $\mathrm{D} 0_{19}$ crystal structure). The alloy also contains $\beta$-phase (TiAl phase with $\mathrm{B} 2$ crystal structure) and $\mathrm{Ti}_{5} \mathrm{Si}_{3}$ precipitates. More detailed descriptions of the microstructure can be found in References 1 and 12 .

Samples for mechanical testing were cut parallel to the axis of the rod by spark erosion and sliced into dogbone-shaped samples with thickness of $0.4 \mathrm{~mm}$, length $28 \mathrm{~mm}$, and width $8 \mathrm{~mm}$. The samples were then mechanically polished to a thickness of $0.2 \mathrm{~mm}$. The final sample had a gage volume of $10 \times 2 \times 0.2 \mathrm{~mm}^{3}$.

The tests were performed in vacuum. The temperatures ranged from $700{ }^{\circ} \mathrm{C}$ to $900{ }^{\circ} \mathrm{C}$ and the stresses from 100 to $450 \mathrm{MPa}$. The strain of the specimen was measured with two "rod-pipe" extensometers coupled to linear variable differential transformers (LVDTs). Three LVDTs were used: two of them were fixed to the upper sample clamp and one was fixed to the lower sample clamp for temperature compensation.

In-situ irradiation creep under He implantation was performed at the compact cyclotron of Forschungszentrum Juelich. The creep testing device and specimen geometry were the same as for the tests without irradiation. The thickness of the samples was $0.2 \mathrm{~mm}$ to allow through irradiation of the helium ions. The $10 \times 2 \times 0.2 \mathrm{~mm}^{3}$ dog-bone samples were homogeneously implanted under uniaxial stress. $4 \mathrm{He} 2+$ ions of $24 \mathrm{MeV}$ passing through a magnet scanning system and a degrader wheel with $24 \mathrm{Al}$ foils of variable thicknesses were employed. Typical implantation rates were $0.02 \mathrm{appm}$ (atom parts per million) helium per second. The concurrent production of displacement damage was calculated by TRIM and SRIM ${ }^{[13,14]}$ for a displacement threshold energy of $40 \mathrm{eV}$ and a binding energy of $2 \mathrm{eV}$. This gives per implanted $\mathrm{He}$ atom 128 displacements on the front side and 70 on the back side,

Table I. Chemical Composition of the Intermetallic Alloy ABB-2

\begin{tabular}{lcccccccc}
\hline Element & $\mathrm{Ti}$ & $\mathrm{Al}$ & $\mathrm{W}$ & $\mathrm{Si}$ & $\mathrm{Fe}$ & $\mathrm{O}$ & $\mathrm{H}$ & $\mathrm{N}$ \\
\hline At. pct & balance & 46.11 & 2.02 & 0.48 & 0.017 & 0.168 & 0.040 & 0.093 \\
Wt pct & balance & 30.26 & 9.00 & 0.32 & 0.044 & 0.077 & 0.002 & 0.009 \\
\hline
\end{tabular}

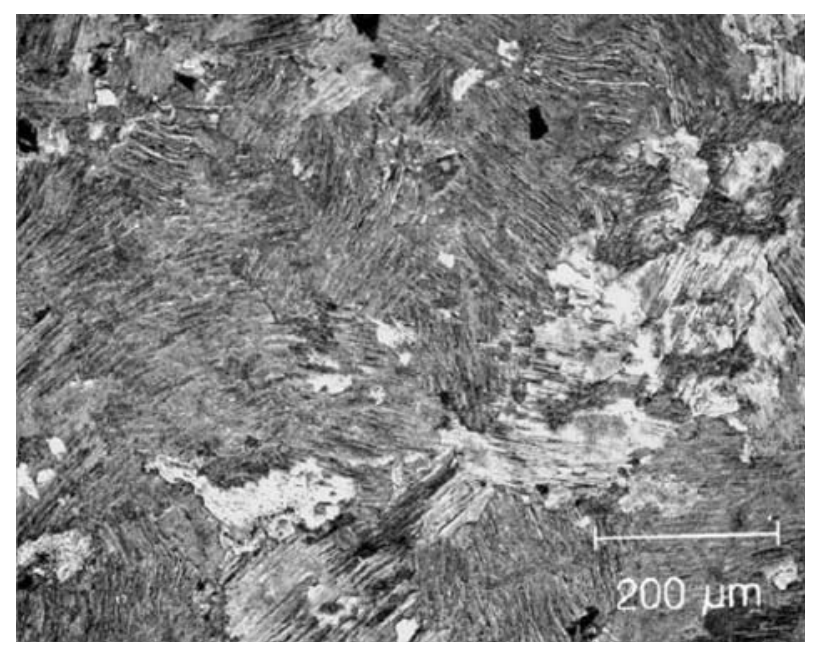

Fig. 1-Typical microstructure of the investigated ABB-2 alloy (optical micrograph).

averaging 117 displacements per He ion. From this, a displacement rate of about $2.3 \cdot 10^{-6}$ dpa (displacements per atom) per second is derived. Due to the high costs for in-beam testing, only short time experiments (typically, 10 hours) were performed. This limits the total dose to about $0.2 \mathrm{dpa}$. This is important with respect to the interpretation of the results, as shown in Section IV. In the case of the in-beam tests, the temperature was measured with a pyrometer that had been calibrated with a thermocouple spot welded to a reference sample. Temperature control in the thermal creep equipment was done with K-type thermocouples located very close to the sample surface. Also, this measurement was calibrated with thermocouples spot welded to a reference sample. Details of the experimental setup are described in Reference 15.

\section{RESULTS}

\section{A. Thermal Creep}

The creep curves showed the expected three stages. Minimum creep rates and stresses measured at $900^{\circ} \mathrm{C}$ were fitted to a Norton equation, and a stress exponent of 6.3 was obtained by linear regression. Figure 2 compares strain rates and the stress exponent at $900{ }^{\circ} \mathrm{C}$ with the corresponding data at lower temperatures. Own data measured at lower temperatures are also shown. They fit very well into the data from the literature,${ }^{[1]}$ which can be taken as an indication that the sample geometry chosen has no measurable effect on the results. The stress exponent determined at $900{ }^{\circ} \mathrm{C}$ is slightly below the ones determined at lower temperatures. Considering the limited amount of tests and the fact that creep tests (stress rupture as well as creep curves) show a considerable scatter (e.g., Figure 10 in Reference 1), a good agreement was found.

Figure 3 compares the strain rates of thin miniaturized samples with the strain rates of standard samples at a constant stress of $300 \mathrm{MPa}$; the strain rates are given 


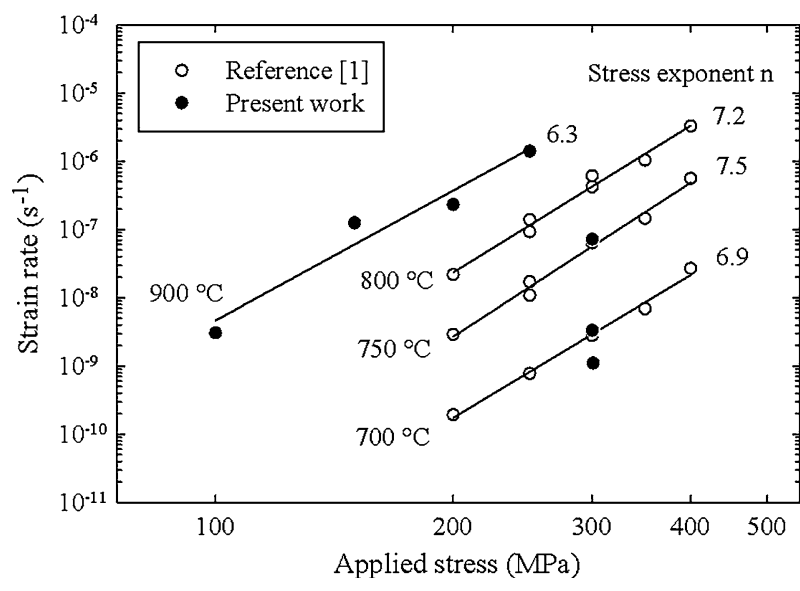

Fig. 2-Strain rates as a function of applied stress. The creep temperatures and the stress exponents, $n$, are indicated in the figure. The creep tests at $900{ }^{\circ} \mathrm{C}$ were performed on thin miniaturized samples. The other creep tests were performed on standard samples with a gage length of $13 \mathrm{~mm}$ and diameters ranging from 3.5 to $5.5 \mathrm{~mm}$.

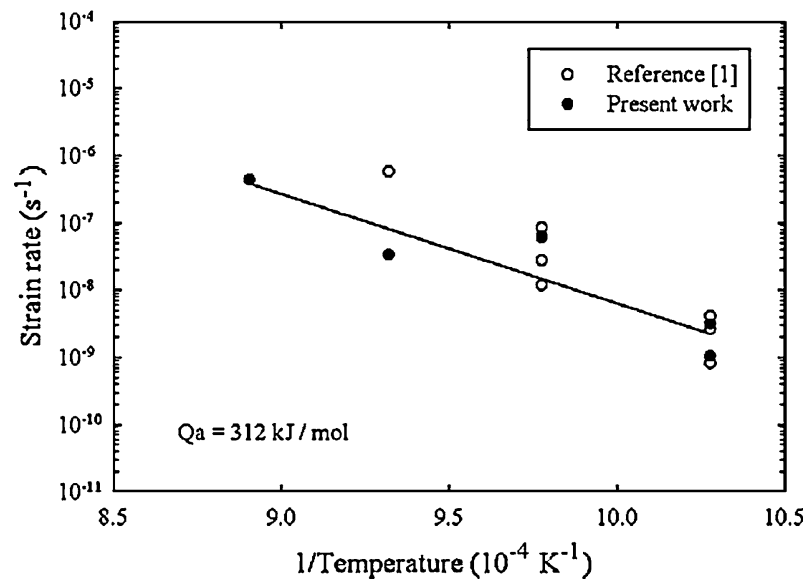

Fig. 3-Strain rate as a function of reciprocal temperature at a constant stress of $300 \mathrm{MPa}$, for both thin miniaturized samples and standard samples.

as a function of reciprocal temperature. These data were used to determine the apparent activation energy $Q_{a}$ for creep given by the Bailey-Norton law:

$$
\dot{\varepsilon}=A_{2} \sigma^{n} \exp \left(-\frac{Q_{a}}{\mathrm{R} T}\right)
$$

where $A_{2}$ is a constant, $T$ the absolute temperature, and $\mathrm{R}$ the universal gas constant.

The value determined for $Q_{a}$ was $312 \mathrm{~kJ} / \mathrm{mol}$. This value is lower than the value of $427 \mathrm{~kJ} / \mathrm{mol}$ reported for standard samples in Reference 1. However, it is fair to say that adding data to a linear curve, which is based on a few values only, can change the slope, particularly for scattering data (as indicated just previously). An influence of different sample geometries might exist, but it is not considered as being very significant here. The thin miniaturized samples might have a larger scatter than standard samples, where the microstructure is averaged

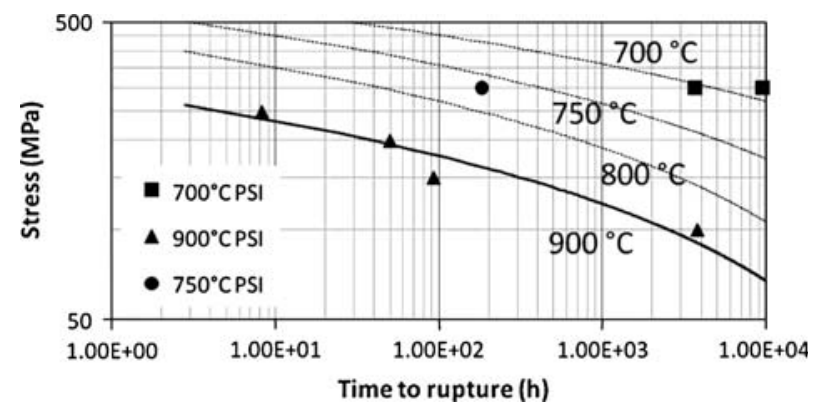

Fig. 4 - Stress rupture curves for different temperatures. The lines for $700{ }^{\circ} \mathrm{C}, 750{ }^{\circ} \mathrm{C}$, and $900{ }^{\circ} \mathrm{C}$ represent the mean values given in Ref. 1. Data points with PSI represent measured own data.

over a higher number of grains. Such effects were found, e.g., in industrial residual life assessments of power plant components. ${ }^{[16]}$

Stress rupture curves are shown in Figure 4. Besides the tests at $900{ }^{\circ} \mathrm{C}$, also tests at lower temperatures were performed to check the consistency of the data.

The fractures surfaces of samples crept at $800{ }^{\circ} \mathrm{C}$ and $900{ }^{\circ} \mathrm{C}$ were investigated with scanning electron microscopy (SEM). Figure 5(a) shows the fracture surface of a sample crept at $900{ }^{\circ} \mathrm{C}$ at a stress of $250 \mathrm{MPa}$. Figure 5(b) shows a crack propagating transgranularly along phase boundaries. The creep area of the fracture surface has a brittle appearance on which the lamellar structure can still be seen. The presence of tungsten-rich $\beta$-particles along the boundaries can also be seen. Tungsten has been reported to act as a solid solution strengthener of the $\beta$ phase, and the $\beta$ phase contains a larger atomic percent of W than either the $\gamma$ phase or the $\alpha_{2}$ phase. ${ }^{[17]}$ A similar behavior was found also at a temperature of $800{ }^{\circ} \mathrm{C}$.

\section{B. Irradiation Creep}

Irradiation creep occurs in metals at temperatures below approximately $600{ }^{\circ} \mathrm{C}$ when irradiation and mechanical loads are simultaneously applied. Irradiation creep experiments can be performed with pressurized tubes being exposed to neutron irradiation in reactors (e.g., Reference 18). Often also ion implantation of thin tensile samples in accelerators is used. In our case, irradiation creep experiments were performed with $\mathrm{He}$ ions in an accelerator at $300^{\circ} \mathrm{C}$ and $500{ }^{\circ} \mathrm{C}$. Irradiation creep is frequently described in terms of the irradiation-creep compliance, $C$. This quantity is related to creep strain rate, $\dot{\varepsilon}$, stress, $\sigma$, and dose rate, $\mathrm{d} \dot{\mathrm{p} a}$, by the following relationship:

$$
C=\dot{\varepsilon} /(\sigma \cdot \mathrm{dp} \mathrm{a})
$$

Figure 6 shows strain rate/displacement rate as a function of the applied stress. According to literature expectations, a linear relationship should exist between the two quantities, becoming eventually parabolic at high stresses. The scatter of the data and the limited amount of tests do not allow for a more detailed analysis, which does not have a severe impact on our first assessment of the potential of this material. There is 

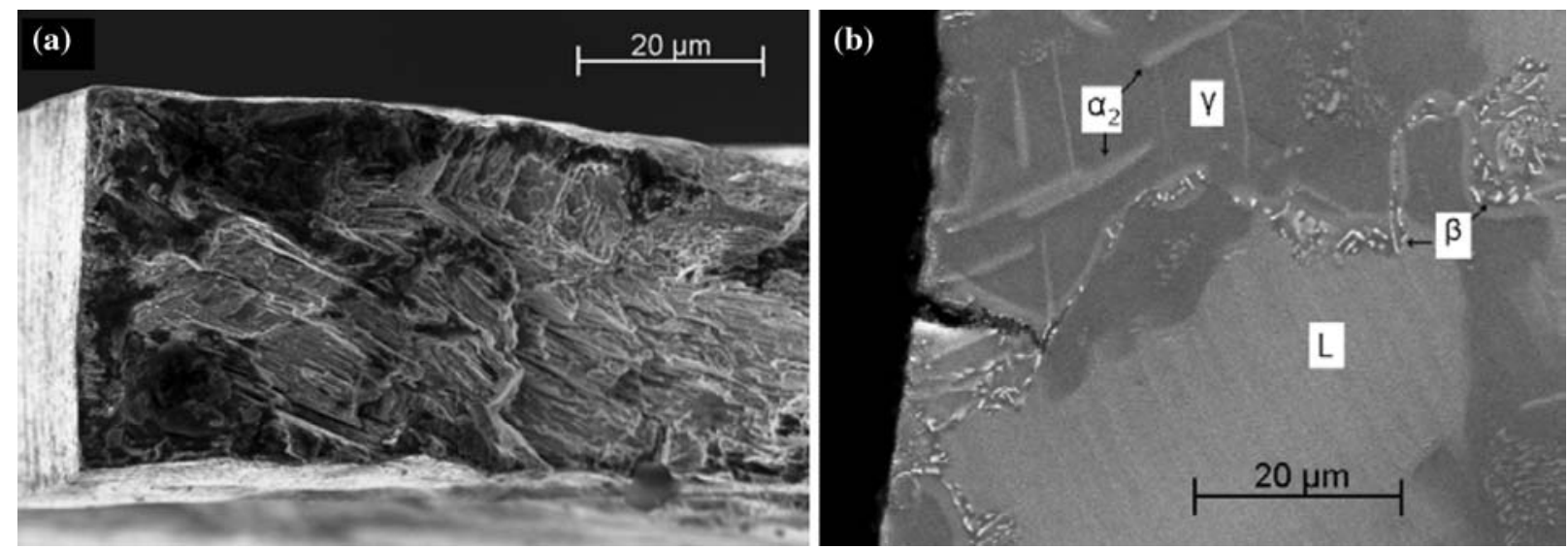

Fig. 5- SEM micrograph of a crack from a sample crept at $900{ }^{\circ} \mathrm{C}$ and $250 \mathrm{MPa}$. (a) Side view of creep crack. The direction of the applied stress $\sigma$ is perpendicular to the crack. (b) Enlarged part of (a), showing an initiated microcrack (L: lamellar region, $\gamma: \gamma$ phase, $\alpha_{2}: \alpha_{2}$ phase, and $\beta: \beta$ precipitates).

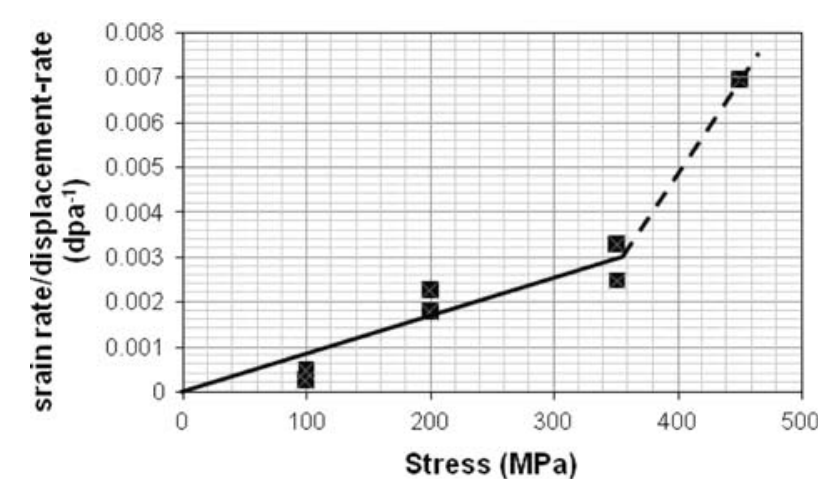

Fig. 6-Dpa rate normalized irradiation creep strain as a function of stress.

only one point (at the highest stress level) indicating an eventual deviation from linear. Therefore, a linear relationship going through the origin was assumed. For the chosen irradiation conditions, the irradiation creep compliance could be determined to be $8 \cdot 10^{-6}$, (MPaddpa). At least for stresses up to $300 \mathrm{MPa}$, this approach is justified for our assessment of the potential of TiAl for advanced nuclear applications. The temperature dependence of the compliance is expected to be very low, and it was not further investigated here.

This compliance compared very well with the average compliance found for different ferritic ODS steels (including PM2000), ${ }^{[19]}$ which was determined to be $8.9 \cdot 10^{-6} /(\mathrm{MPa} \cdot d \mathrm{pa})$. From these findings, it can be assumed that the TiAl alloys behave in a manner similar to ferritic materials, which would make them superior to austenitic materials with respect to irradiation behavior (e.g., Reference 20).

\section{DISCUSSION OF THE RESULTS}

Our investigations were performed to assess the potential of TiAl for advanced nuclear applications. The results therefore are put into relation with other materials for such applications. These are the nickelbase superalloys (taking IN617 as an example) and the ferritic ODS steels (taking PM2000 as an example).

In contrast to the very well investigated standard alloy for the highest temperatures in HTR environment, i.e., IN617 ${ }^{[21,22]}$ only limited creep rupture data exist for PM2000 and ABB-2. For IN617, a thorough evaluation of stress rupture properties could be used for the comparison. ${ }^{[23]}$ For an assessment of creep rupture curves of ABB-2 and PM2000, it was necessary to construct them from the existing scarce data with a suitable parametrization allowing also extrapolation to longer rupture lives. There are different methods available, which were comprehensively discussed, e.g., in Reference 24. Several important extrapolation methods are based on the fact that for metallic materials at a particular stress, a linear relationship between the creep rupture time $\log 10\left(t_{R}\right)$ and the testing temperature $T$ or the inverse testing temperature $1 / T$ exists. As for hightemperature materials, slightly better correlations were found using the linear dependence from $T ;{ }^{[25]}$ we will base our extrapolations on this fact and use an extrapolation that was very successfully applied for different materials in an industrial laboratory. ${ }^{[25,26]} \mathrm{It}$ relates $\log 10\left(t_{R}\right)$, the stress $\sigma$, and the absolute temperature in the following form:

$$
\log 10\left(t_{R}\right)=T \cdot(A \cdot \log 10(\sigma)+B \cdot \sigma+C)+D
$$

with the constants $A, B, C$, and $D$.

For ABB-2, we used the creep rupture data published in Reference 1 and our own data for evaluation. The data for PM2000 were established with this method in another article. ${ }^{[27]}$ For the sake of consistency, we also analyzed the existing IN617 data according to Eq. [3] and found an extremely good agreement with the literature. ${ }^{[23]}$ The calculated $10^{4}$-hour creep rupture strengths were plotted in Figure 7 as a function of temperature. From Figure 7 follows that up to about $900{ }^{\circ} \mathrm{C}$, the investigated TiAl is clearly better than PM2000. It is also expected to possess a better stress rupture behavior than IN617 in the entire temperature 
range. At the highest temperatures, the improvement of the creep rupture strength of the intermetallic is roughly a factor of 2 (in stress) compared with IN617.

Thermal creep and irradiation creep occur at different temperatures. The combination of both is shown in Figure 8 , where strain rates at different temperatures

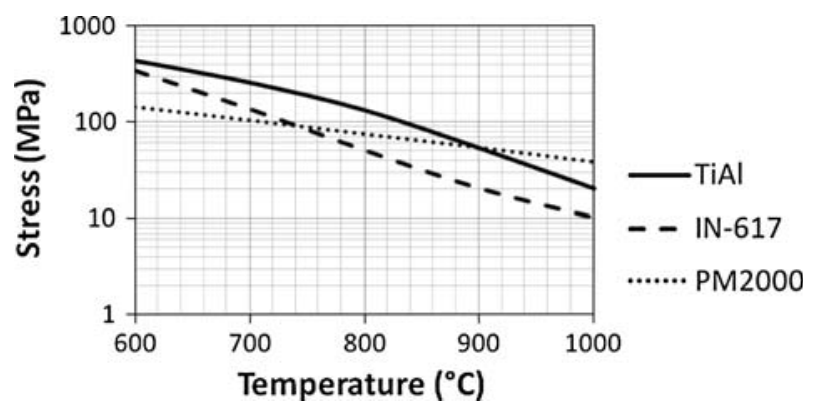

Fig. 7-10,000 h creep rupture strength for the different materials considered. Data treated according to Eq. [3].

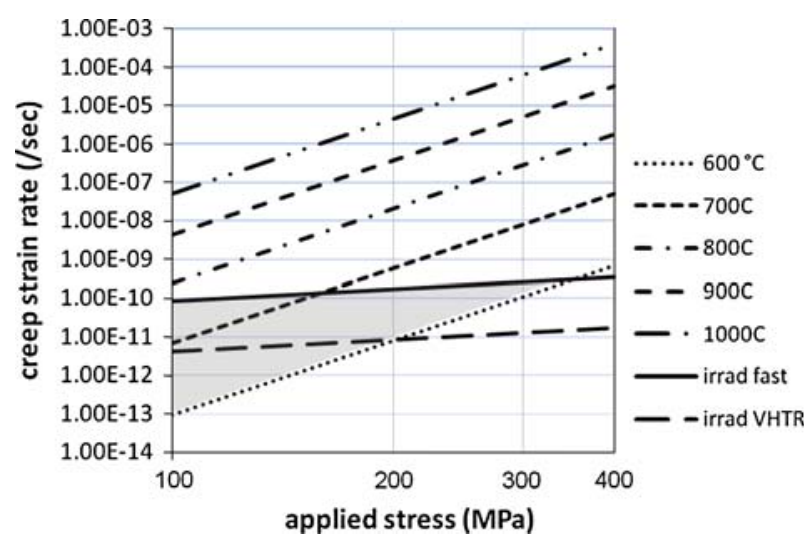

Fig. 8-Thermal and irradiation creep rates as a function of the applied stress at different temperatures. Shaded area represents area of interaction between both mechanisms. were plotted as a function of the applied stress. The data for irradiation creep were derived using the measured irradiation creep compliance for He implantation. The irradiation creep rates depend on the dpa rates. Therefore, two cases were chosen: one for fast reactors corresponding with $200 \mathrm{dpa} / 60$ years (irradiation fast) and the other for a very high-temperature reactor corresponding with $10 \mathrm{dpa} / 60$ years (irradiation VHTR).

The shaded area shows the conditions under which an interaction between thermal creep and irradiation creep is expected.

We would finally like to demonstrate the technical importance of irradiation creep at lower temperatures for TiAl and ferritic ODS steels, taking the relaxation behavior as an example. Figure 9(a) shows the relaxation behavior using the irradiation creep compliances determined with He implantation $\left(8 \cdot 10^{-7} /(\mathrm{MPa} \cdot \mathrm{dpa})\right.$ for TiAl and $8.9 \cdot 10^{-7} /(\mathrm{MPa} \cdot \mathrm{dpa}$ ) for PM2000). However, for comparison with reactor conditions, it is necessary to make a correction to the compliance measured. Ryazanov has shown by an evaluation of a variety of irradiation creep stress performed under different conditions (ion implantation, fast neutrons) ${ }^{[28]}$ that the compliance remains constant for total doses above 2 dpa. For doses below $2 \mathrm{dpa}$, the irradiation creep compliance increases almost linearly with decreasing doses. Our irradiation creep tests were performed at relatively high dose rates, but the total dose per test was about $0.2 \mathrm{dpa}$ only. Applying this dose correction for our measurements a compliance of $8 \cdot 10^{-7} /(\mathrm{MPa} \cdot \mathrm{dpa})$ for TiAl and $8.9 \cdot 10^{-7} /(\mathrm{MPa} \cdot d \dot{p a}$ ) for PM2000 can be expected under reactor conditions (Figure 9(b)). For the assessment of thermal relaxation of TiAl minimum creep rates and the Norton equation (Eq. [2]) were used. For PM2000 the Monkman-Grant relationship between time to rupture and secondary creep strain rates was chosen (see also Reference 27). The results (gained by numerical integration) are plotted in Figures 9(a) and (b) for different dpa rates, representing a thermal reactor $(10 \mathrm{dpa} / 60$ years $)$ and a typical fast reactor

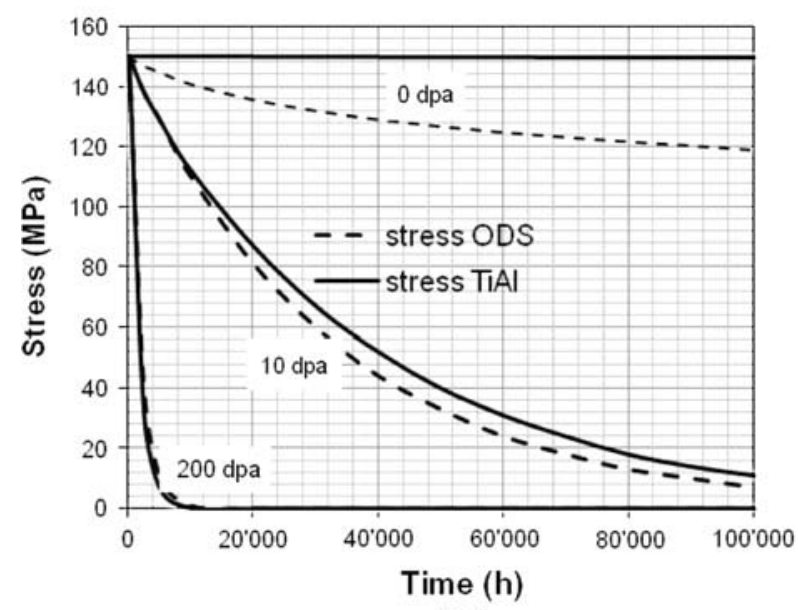

(a)

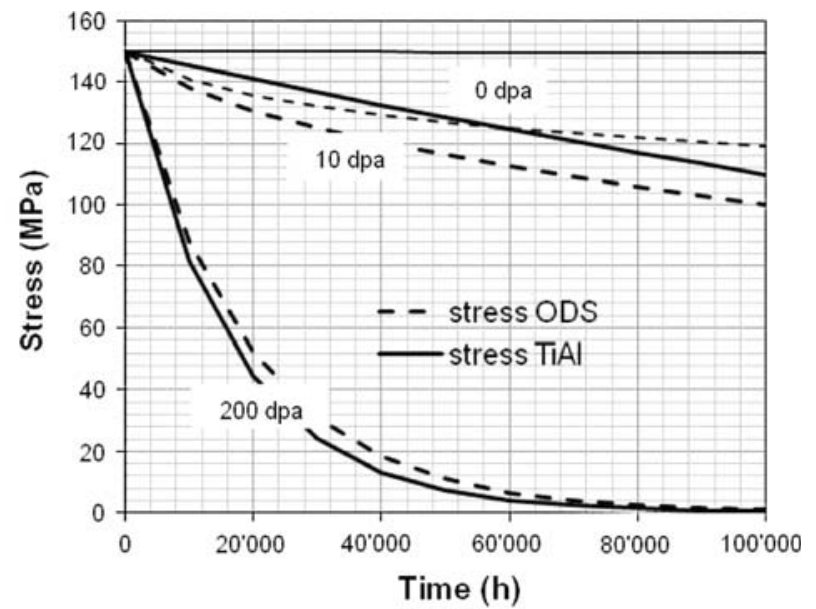

(b)

Fig. 9-Influence of irradiation on the relaxation behaviour $\left(100^{\prime} 000\right.$ hours $\left./ 500{ }^{\circ} \mathrm{C}\right)$ of an ODS alloy (PM2000) and the investigated TiAl (ABB-2) at $10 \mathrm{dpa} / 60$ years (VHTR) and $200 \mathrm{dpa} / 60$ years (GFR). (a) He-implantation (total dose $0.2 \mathrm{dpa}$ ) (b) Reactor (total dose $>2 \mathrm{dpa}$ ). 
(200 dpa/60 years). The relaxation behavior is thermally dominated at low dpa rates. At high dpa rates, relaxation is exclusively governed by irradiation creep.

The nickel-base alloy was not included in the irradiation creep considerations, because the irradiation properties are better for ferritic alloys than for austenites and nickel is very prone to helium embrittlement due to the transmutation production of helium via a nuclear reaction.

\section{CONCLUSIONS}

Thermal and irradiation creep properties of a cast $\gamma$-TiAl based intermetallic alloy of type Ti-46Al-2W-0.5Si (at. pct) were investigated. The results were used together with existing literature data to assess the mechanical potential of this material for structural applications in advanced nuclear plants.

1. The stress rupture properties were in the entire temperature range slightly better (factor 1.5 in stress) than the ones of the nickel-base alloy IN617.

2. The irradiation creep behavior, which is the predominant creep-deformation mechanism at temperatures below about $600{ }^{\circ} \mathrm{C}$, was comparable with ferritic materials and therefore better than for austenitic materials.

These facts demonstrate that there is a good potential of such a TiAl for advanced structural nuclear applications. Questions of corrosion behavior in reactor helium or other advanced nuclear environments, thermal stability of the microstructure, possible helium embrittlement, and component manufacturing (including economic considerations and low room-temperature ductility), however, need to be investigated.

\section{REFERENCES}

1. J. Lapin and M. Nazmy: Mater. Sci. Eng. A, 2004, vol. 380, pp. 298-307.

2. E.A. Loria: Intermetallics, 2000, vol. 8, pp. 1339-45.

3. T. Tetsui: Mater. Sci. Eng. A, 2002, vols. 329-331, pp. 582-88.

4. A Technology Roadmap for Generation IV Nuclear Systems, U.S. Department of Energy, 2002, http://gif.inel.gov/roadmap/pdfs/ gen_iv_roadmap.pdf.
5. M. Es-Souni, A. Bartels, and R. Wagner: Acta Metall. Mater., 1995, vol. 43 (1), pp. 153-61.

6. M.A. Morris and T. Lipe: Intermetallics, 1997, vol. 5, pp. 329-37.

7. T.A. Parthasarathy, M.G. Mendiratta, and D.M. Dimiduk: Scripta Mater., 1997, vol. 37 (3), pp. 315-21.

8. J.G. Wang, L.M. Hsiung, and T.G. Nieh: Intermetallics, 1999, vol. 7, pp. 757-63.

9. L.M. Hsiung and T.G. Nieh: Intermetallics, 1999, vol. 7, pp. 82127.

10. C.E. Wen, K. Yasue, J.G. Lin, Y.G. Zhang, and C.Q. Chen: Intermetallics, 2000, vol. 8, pp. 525-29.

11. M. Nazmy and M. Staubli: U.S. Patent 5,207,982 and EP. 45505 B1.

12. W.M. Yin, V. Lupinc, and L. Battezzati: Mater. Sci. Eng. A, 1997, vols. 239-240, pp. 713-21.

13. J.P. Biersack and L.G. Haggmark: Nucl. Instr. Meth., 1980, vol. 174, p. 93.

14. J.F. Ziegler, J.P. Biersack, and U. Littmark: The Stopping and Range of Ions in Solids, Pergamon, New York, NY, 1985.

15. P. Jung, A. Schwartz, and H.K. Sahu: Nucl. Instr. Meth. A, 1985, vol. 234, pp. 331-34.

16. W. Hoffelner, M. Staubli, A. Czeratzki, and R.B. Scarlin: Residual Life Assessments of Steam Turbine Components with the "Isostress"-Method, ABB Metals Laboratories, Baden, Switzerland, unpublished research, 1982-1984.

17. W.M. Yin, V. Lupinc, and L. Battezzati: Mater. Sci. Eng. A, 1997, vols. 239-240, pp. 713-21.

18. R.J. Puigh: in Effects of Radiation in Materials, F.A. Garner and J.F. Perrin, eds., ASTM STP 870, ASTM, Philadelpia, PA, 1985, pp. 7-18.

19. J. Chen, M.A. Pouchon, A. Kimura, P. Jung, and W. Hoffelner: J. Nucl. Mater., 2009, vols. 386-388, pp. 143-46.

20. P. Yvon and F. Carré: J. Nucl. Mater., 2009, vol. 385, pp. 217-22.

21. F. Schubert, U. Bruch, R. Cook, H. Diehl, Ph.J. Ennis, W. Jakobeit, H.J. Penkalla, E. te Heesen, and G. Ullrich: Nucl. Technol., 1984, vol. 66, pp. 227-40.

22. H.-J. Penkalla, H.-H. Over, and F. Schubert: Nucl. Technol., 1984, vol. 66, pp. 685-92.

23. S. Chandra, R. Cotgrove, S.R. Holdsworth, M. Schwienheer, and M.W. Spindler: Creep Rupture Data Assessments of Alloy 617, Creep and Fracture in High Temperature Components, ECCC Creep Conf., London, Sept. 2005, pp. 178-88.

24. J.F. dos Reis Sobrinho and L. Oliveira Bueno: Rev. Matéria, 2005, vol. 10 (3), pp. 463-71.

25. W. Hoffelner: in High Temperature Alloys for Gas Turbines and other Applications, W. Betz, R. Brunetaud, D. Coutsouradis, H. Fischmeister, T.B. Gibbons, I. Kvernes, Y. Lindblom, J.B. Marriott, and D.B. Meadowcroft, eds., D. Reidel Publishing Company, Dordrecht, 1986, pp. 413-40.

26. W. Hoffelner and M. Staubli: ABB Metals Laboratories, Baden, Switzerland, unpublished research, 1985.

27. J. Chen and W. Hoffelner: J. Nucl. Mater., 2009, vol. 392 (2), pp. $360-63$.

28. A.I. Ryazanov: "Modern Problems of Irradiation-Induced Plastic Deformation in Irradiated Structural Materials," Poster presented at Dislocations 2004, La Colle-sur-Loup, France, Sept. 13-17, 2004. 